\title{
BMJ Global Health Health system governance: a triangle of rules
}

\author{
Seye Abimbola (1) 1,2
}

To cite: Abimbola S. Health system governance: a triangle of rules. BMJ Global Health 2020;5:e003598. doi:10.1136/ bmjgh-2020-003598

Received 1 August 2020 Accepted 1 August 2020

\section{Linked}

- http://dx.doi.org/10.1136/ bmjgh-2020-002404

- http://dx.doi.org/10.1136/ bmjgh-2020-002533

Check for updates

(C) Author(s) (or their employer(s)) 2020. Re-use permitted under CC BY-NC. No commercial re-use. See rights and permissions. Published by BMJ.

${ }^{1}$ School of Public Health, University of Sydney, Sydney, New South Wales, Australia

${ }^{2}$ The George Institute for Global Health, Sydney, New South Wales, Australia

Correspondence to Dr Seye Abimbola;

Seye.Abimbola@sydney.edu.au

\section{INTRODUCTION}

One well-known challenge of working in multidisciplinary fields (such as global health and health systems) is finding a language that is understandable, recognisable and useable by people from varying backgrounds. Without such language, it is difficult to have discussions that are necessary for multidisciplinary fields to grow and achieve their purpose. Forging a common language requires deliberate effort. Having a widely accepted framework can help, especially when accompanied by theories that connect the categories within the framework. ${ }^{1}$ Even then, some issues or subfields require working at a common language more than others - for example, governance, which, as far as words and concepts go, is remarkably nebulous. $^{2}$

In this edition of BMJ Global Health, Bigdeli et a $\vec{l}$ offer a promising framework; a 'triangle of persons', if you will, to explore hitherto 'missing links' in health system governance. Each of the three nodes of this triangle is occupied by one category of persons, that is, policy-makers, providers and people. This triangle began its life in the 2004 World Development Report, ${ }^{4}$ as a map of stakeholders involved in accountability relations in the health system. It has gone through several iterations, interpretations and applications. ${ }^{5-7}$ However, the current 'triangle of persons' is particularly clear, detailed and succinct. It explores what happens between the nodes. And more than previous iterations, it also explores what happens within each node.

In an accompanying paper, Meessen celebrates a welcome reboot in the discourse on and study of health system governance in global health ${ }^{8}$; a reboot that: (1) de-emphasises normative preoccupations and instead emphasises empirical explorations of health system governance; (2) makes governance more concrete by redefining it in terms of 'making, changing, monitoring and enforcing the formal and informal rules, ${ }^{2}$ that govern 'collective action and decision making in a system'; and (3) shifts focus from governments as singular governing entities to a broader conception of who is involved in governance, by focusing on the rules that determine and emanate from the collective agency of constituted authorities and informal groups.

In this editorial essay, I will connect both works with a 'triangle of rules'. I will then use stylised accounts of experience and evidence to explain this 'triangle of rules', illustrate its application and the complementary advantage of using it alongside the "triangle of persons'. These stylised accounts point at potential middle-range theories and empirical explorations of even more 'missing links' in health system governance.

\section{THE TRIANGLE OF PERSONS}

It is likely that the expression 'triangle of persons' was first used in $1979^{9}$ by Malan, who put together two triangles (figure 1) to provide a simple, universal framework for psychoanalytic (or psychodynamic) psychotherapy. One of them, the 'triangle of persons', depicts relationships between a patient and three sets of persons-the past 'significant persons' (eg, parents), the therapist and the current 'significant persons' (eg, spouse). The next is the 'triangle of conflicts'. The 'triangle of conflicts' is less tangible, but it is no less consequential. It depicts what animates relationships among persons: defences (eg, changing and minimising the subject), anxieties (eg, worry and panic) and feelings (eg, anger and grief). The 'triangle of conflicts' shows how defences and anxieties can block the expression of feelings. The 'triangle of persons' shows how these patterns of behaviour began with past significant persons, are maintained with current significant persons and get played out with the therapist. ${ }^{9}$ Each node of one triangle is linked to the corresponding node on the other triangle.

Frameworks aim to simplify, to clarify. Malan's triangles are no exception. Each 


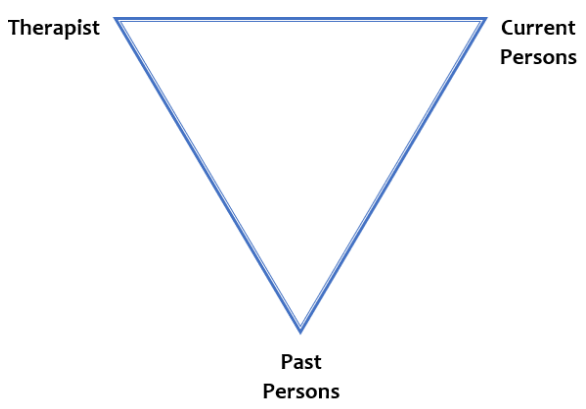

Triangle of Person

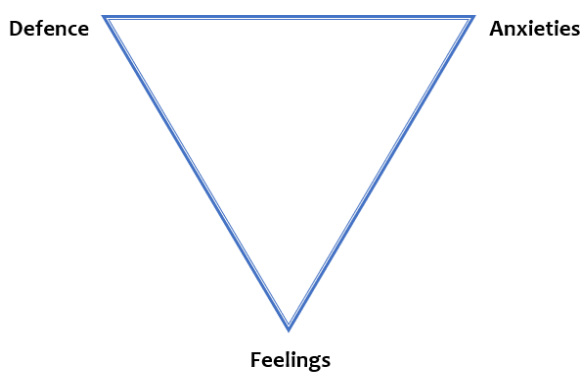

Triangle of Conflicts

Figure 1 The two triangles to represent what happens in psychoanalytic (or psychodynamic) psychotherapy: defences and anxieties can block the expression of true feelings; and these patterns began with past persons, are maintained with current persons and are often enacted with the therapist.

triangle was not originally developed by Malan. But by putting them together, Malan achieved a framework with an explanatory power that far surpasses that of each triangle, when used separately. ${ }^{10}$ The triangles continue to be used today. ${ }^{11}$ They may be criticised for their tendency to oversimplify. But what having two triangles in the framework demonstrates is that there are limits to simplification. One triangle was too simple to capture the necessary complexity involved in psychotherapy. This is also the case with the 'triangle of persons' put forward by Bigdeli et al. Like Malan's triangles, the health system governance 'triangle of persons' requires a second, complementary triangle. Alone, its explanatory power to reveal the missing links and capture the complexity of health system governance will likely remain limited. Indeed, there is much more to health system governance than can be revealed or captured in one triangle-perhaps not even two.

\section{THE TRIANGLE OF RULES}

The distinction between the 'triangle of persons' and the 'triangle of rules' is subtle. Like Malan's triangles, one is of persons, and the other is about what governs their actions, decisions and relations (figure 2). The 'triangle of rules' is about the rules that persons make, change, monitor and enforce; the rules that govern their actions, decisions and relations; and the rules that emanate from those actions, relations and decisions. I have used this 'triangle of rules', often implicitly, in my own work and also in reinterpreting others' work. The 'triangle of rules' was inspired by the Institutional Analysis and Development framework, which was developed by Elinor Ostrom and colleagues, ${ }^{13} 14$ even though they did not conceive of any aspect of their framework as a triangle, but as 'three worlds of action, ${ }^{15}$ or 'three levels of rules'." Before sharing how one may use the 'triangle of rules' and illustrate its potential, I will first describe what occupies its three nodes (operational, collective and constitutional rules) and what happens in the spaces between them (figure 3).

1. Operational rules emerge from individual choices and the market forces of demand and supply. They determine how individual health system actors implement practical day-to-day decisions; how, for example, market rules (in the form of prices), informal rules (eg, social norms) and formal rules (eg, government regulations) determine how people in a community seek, use (ie, demand) and provide (ie, supply) health and social services. Operational rules are influenced by collective rules and constitutional rules. Constitutional rules may directly influence operational rules. Constitutional rules may also influence operational rules indirectly through their influence on collective rules. $^{14-18}$

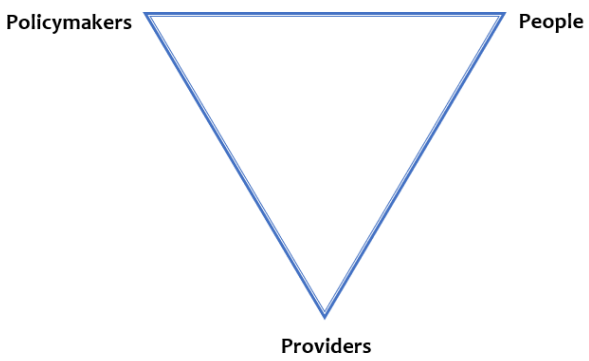

Triangle of Persons

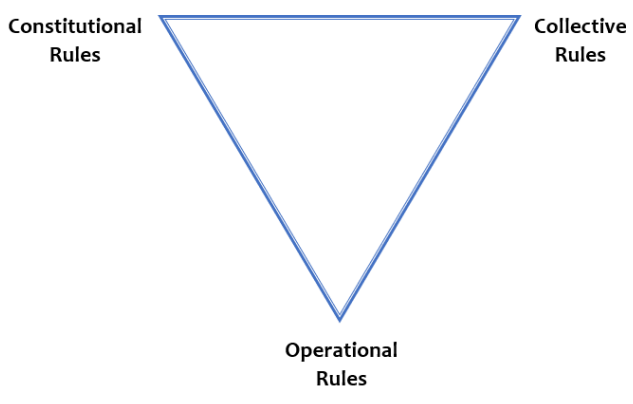

Triangle of Rules

Figure 2 The two triangles represent what happens in health system governance: policy-makers, people and provider make, change, monitor and enforce (formal and informal) rules, which may be constitutional, collective and operational rules, and these rules in turn influence their actions, decisions and relations. 


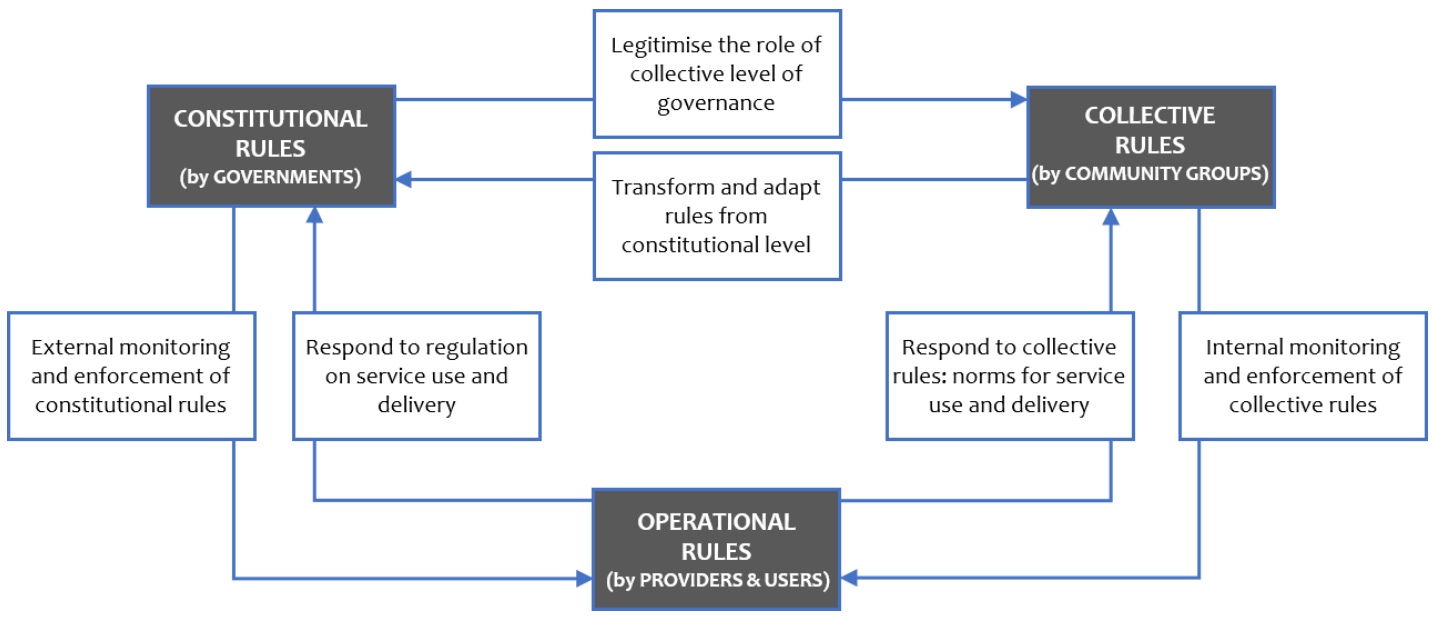

Figure 3 The 'triangle of rules' showing bi-directional relationships between each of the nodes of the triangle with the other two nodes, using the example of rules that govern service delivery within a community.

2. Collective rules are typically made by 'close-to-ground' governing entities, which may be informal or formally constituted. Collective rules influence day-today operational activities on the demand and supply side. On the demand side, 'close-to-ground' governing entities include community groups or representatives, such as community health committees, religious groups or women's groups. On the supply side, 'close-to-ground' governing entities may include locally based professional groups, for example, of midwives or traditional birth attendants. They may also include close-to-ground governments, for example, a district government or local council (when operating at a small scale). Of note, how collective rules are made, changed, monitored and enforced is often determined (especially when they are formal rules) by another category of rules-constitutional rules. In addition, to reach the operational level, constitutional rules may pass through and be modified by collective governance actors. ${ }^{14-18}$

3. Constitutional rules are made, typically at a distance, by governments and government-like entities such as large and influential non-governmental organisations or religious organisations with national (or large scale) jurisdiction and reach. Constitutional rules can determine who has the power to make operational rules and on what terms such persons make operational rules. They can also determine who has the power to make collective rules and on what terms. Constitutional rules can also determine how rules at the collective and operational nodes (or levels) are made, changed, monitored and enforced. ${ }^{14-18}$

The rules-in-use (de facto rules) at the operational level may diverge significantly from rules-in-form (de jure rules) at the constitutional level. An important mediator of that gap is actors at the collective level. ${ }^{1417}$ For example, consider the operational rule that determines the opening hours for outpatient services in a public sector health facility. Constitutional rule-making entities (say, policy-makers at the capital city) may decide that the operational rule should be
09:00 to 17:00. Or they may decide that such a rule should be made at the collective level, say by the council of chiefs (or by the governing board of each health facility or by the health committee in each community). And the council of chiefs may, in turn, decide that such a rule should instead be made by operational level actors; say the manager or health worker in charge of the facility.

In a scenario in which such a rule is only made, changed, monitored and enforced at the constitutional level, two problems may arise. First, constitutional actors are distant from this health facility and may not be able to monitor and enforce this 09:00 to 17:00 rule. Second, distant constitutional level actors may also be unable to use information and feedback from the community to make and change rules in a way that is responsive to the needs and preferences of people in the community. Women in the community may be dissatisfied with the 09:00 to 17:00 rule, perhaps because on market days, they are unable to take their children for immunisation during those hours. So, on those days, they want the health facility to open earlier, at say 07:00, so that they can visit the immunisation clinic before heading to the market.

If constitutional actors are distant and ineffective, collective-level actors may play the role of changing this rule whether or not they have a constitutional mandate to do so. But what if collective actors are also absent or too disengaged; say, a council of chiefs that does not care? What you then have is a situation in which the de facto rules (rules-in-use) that govern opening hours may depend only on relationships between demand and supply operational actors. Health workers may do what the women want because their income, sense of fulfilment or social standing depends on it; because it is convenient for them to open early and close early on market days, so they too can shop at the market, or in exchange for a bribe or informal charges.

\section{USING THE TRIANGLE OF RULES}

In my experience, four attributes of rules are worth bearing in mind when using the 'triangle of rules' 
to analyse and explain the impacts of governance on health system performance: (1) rules are best analysed from the bottom up, beginning with operational rules; (2) as health systems are complex and adaptive, rules at different levels function in dynamic balance with one another; (3) rules are mediated by distance and scale; and (4) the power to make, change, monitor and enforce rules may be concentrated or disperse.

\section{Rules are analysed from the bottom up}

The inquiry begins from the operational level. It is where individuals make choices and where rules-in-form transform into rules-in-use. Seeing clearly what shapes and determines rules-in-use from the bottom up can make alternative approaches to addressing governance problems more visible. The question that animates such an inquiry is-what are the rules-in-use at the operational level? Are they rules from the operational arena (eg, the interplay of demand and supply)? Are they rules from the constitutional level? Are they from the collective arena? Or did they result from a combination of processes at two or all three levels? The exploration shines a light on informality; on how rules-in-use diverge from rules-in-form. The question may be why are people in a community seeking care from inappropriate healthcare providers (eg, unlicensed drug sellers, traditional birth attendants, healers or bonesetters) so much that they ignore or take too long to make their way to appropriate providers? ${ }^{19-22}$

Notably, the answer may be found among three sets of contextual factors (see the matrix in figure 4): socioeconomic context (eg, inability to afford formal providers means that people would rather 'shop around' at informal providers); geographical context (eg, the large size of the village means there are many informal providers, and for many in the community, it is difficult to physically access a single formal provider); and institutional (ie, rules-in-use) context of the local healthcare market (eg, the constitutional rules to regulate informal providers are neither monitored nor enforced). ${ }^{14-1723}$ Interacting with one another, all these contextual factors combine to promote or inhibit the emergence of trust, power and accountability relations, which also strongly influence the choice of provider. When constitutional rules are not monitored and enforced, the rules of the marketplace may dominate at the operational level. Or collective rules may dominate. The collective rules may be a 'professional code' among informal providers such that, even if constitutional rules are neither monitored nor enforced, they may continue to refer to formal providers as appropriate.

A strategy to address the problem may be to change existing rules that govern informal providers so that they refer their clients to formal providers or work alongside formal providers. Another may be to spread information about the costs of inappropriate care in the community so people can change their care-seeking behaviours. But these strategies require changing local norms (ie, informal rules), which can take decades to change. ${ }^{20}{ }^{22} \mathrm{~A}$ third strategy is to change constitutional rules to enable the supply of more formal providers or reduce outof-pocket costs of care at formal providers. But these require political engagement strong enough to alter those constitutional rules. A fourth strategy is to improve the monitoring and enforcement of the constitutional rules that limit informal providers. But entrenched local norms and informal practices are hard to regulate at a distance. ${ }^{21} 22$ With a large distance between the constitutional and operational levels, it may be more effective to strengthen collective actors to make new rules or change existing ones in ways they can monitor and enforce.

\section{Rules function in a dynamic balance}

In health systems, rules help to achieve three purposes ${ }^{2324}$ : (a) to provide public goods, for example, rules on using taxes and other collective resources to provide a social safety net and health infrastructures, such as health workers, health facilities and access roads; (b) to

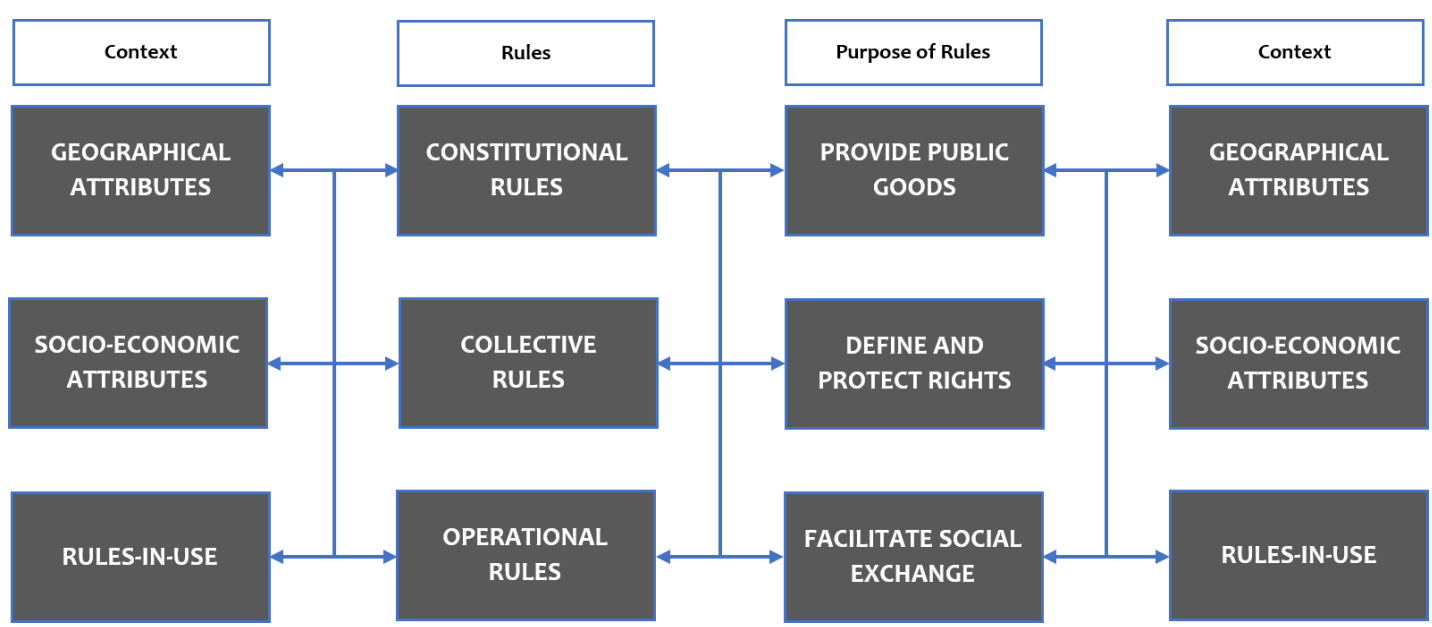

Figure 4 The 'matrix' showing 'rules-in-use' as one of three categories of context: rules-in-use are influenced by the three categories of rules, all of which together influence (are, in turn, influenced by) the three categories of context. The three categories of rules influence the three categories of context through how they influence the provision of public goods, the definition and protection of rights, and the facilitation of social exchange. 
define and protect rights, for example, rules that define and protect the rights and conditions under which individuals and communities benefit from a resource, including the right to access, use and manage public goods such as health facilities and services; and (c) to facilitate social exchange, for example, rules to maximise the benefits from resources and relations, including rules to ensure that information, regulation and coordination work to align demand with supply and vice versa.

Notably, each set of rules may originate from any of the three levels of governance (figure 4) ${ }^{1724}$ functioning in a dynamic balance to achieve these three sets of goals. ${ }^{1723}$ The rules for facilitating transactions, and thus promoting the use of formal providers could be made at any or a combination of the three levels of governance. However, when rules are effectively made, changed, monitored and enforced from the constitutional level, there is less role for collective rules, and so constitutional rules would often obtain at the operational level. ${ }^{171823}$ But the weaker the constitutional level, the more the roles for collective and operational levels. In some instances, this may occur by default. And in others, constitutional actors may deliberately configure the rules such that some are made, changed, monitored and enforced at the collective level, and others at the operational level.

Let us consider another example. Health worker absenteeism. One set of rules determines how many health workers are available in a health system or within a country - that is, rules that provide public goods. Another set of rules determines who has access to those health workers (eg, rules that define the access of rural communities to health workers; say, the rules governing the posting and transfer of health workers to rural communities) - that is, rules that define and protect rights. And yet, another set of rules determine how, once in a community, people access the services which are provided by the health workersare people aware that health workers are available, what time of day they are available, are they available when the community is able to access them, do they provide highquality services and are they responsive to the peoplethat is, rules that facilitate social exchange. ${ }^{19} 202325$

To understand high levels of rural health worker absenteeism, the analyst asks: Are there no rules governing operating hours? (unlikely) Are the constitutional rules not monitored or enforced? (more likely) Are there collective rules that govern operating hours which then allow health workers to be present only when the community needs them most? Are they absent because rules protecting the rights of rural communities to the health workers are inadequate? Are they left to sort out their accommodation when transferred to rural communities? Are they without a travel allowance? Is the collective level of governance absent such that health workers at the operational level make their own rules? ${ }^{2025-29}$ The 'triangle of rules' helps to explore how absenteeism (as are other governance issues) is a complex and adaptive phenomenon. When one level of governance fails, the extent of effects of the failure can be assuaged or compensated for by governance at another level. ${ }^{1718}$

\section{Rules have a distance and scale effect}

In complex and adaptive systems, rules (or institutions) have epistemic properties. In other words, the ways in which rules relate with one another within health systems (ie, institutional arrangements or rule configurations); have different capacities to generate the knowledge and feedback necessary to make, change, monitor and enforce rules effectively, equitably and responsively. ${ }^{1730} 31$ Of note is the distance that may exist between constitutional or collective level and the operational level, and the scale or number of operational units which are the subject of rules. Distance and scale, mediated by power and resources, influence how governance actors use local knowledge and feedback to make, change, monitor and enforce rules.

Take two related scenarios. In the first, the governance of hospitals in a country was decentralised from a national ministry of health to subnational governments. ${ }^{32}$ Predecentralisation, there were, say, 50 hospitals, all run from the 'distant' national ministry of health, that is, with rules from the constitutional level of governance. But each hospital had a governing board, that is, the collective level of governance. Prior to decentralisation, the 'proximate' boards exercised power and discretion in the operational rules governing the day-to-day activities of each hospital. This was in part because the centre was far away from most of the 50 hospitals, thus diminishing the ability of the national ministry of health to make, change, monitor and enforce rules for all 50 hospitals. By design or default, much responsibility to make, change, monitor and enforce rules fell to the boards. But with decentralisation, constitutional governance shifted to 50 locations across the country, which are now 'proximate' to each hospital. Previously influential, each of the 50 hospital boards (collective level) then becomes much less powerful, as the operational day-to-day rules are made, changed, monitored and enforced more directly at (newly decentralised) constitutional levels, that is, by subnational governments, leading to 're-centralisation' and poorer hospital performance. ${ }^{1732} 33$

Now, consider an alternative, almost opposite scenario, in which the governance of primary healthcare facilities was decentralised from an existing subnational government to community health committees. ${ }^{34} 35$ Predecentralisation, the day-to-day operational decisions were determined by the constitutional rules made by the subnational ministry of health for, say, the 50 primary healthcare facilities within the subnational jurisdiction. There was little or no role for collective governance by community health committees. With decentralisation, 'proximate' community health committees (one for each of the 50 health facilities) make, change, monitor and enforce the rules governing the finances of their own health facility. As a result, the performance of the health facilities so governed improves relative to when 
decisions were predominantly made at the constitutional level. ${ }^{173435}$

In both scenarios, what is at play is not just proximity. There is also a scale or numbers effect. Before decentralisation, the governing entity looked after 50 operational units, which effectively dilutes its effectiveness to make, change, monitor and enforce rules. Postdecentralisation, governing entities oversee only one operational unit each. With decentralisation to subnational governments, stronger constitutional governance can reduce the responsibility exercised by default or delegation at the collective level of governance. And with decentralisation to community health committees, stronger collective governance can promote local community autonomy and health facility performance. ${ }^{17}$

\section{Rules have a concentration effect}

The power to make, change, monitor and enforce rules at the operational level can vary from the concentrated power of a private-sector provider who makes and changes rules without consulting another authority (eg, where the constitutional level is weak and there is no governing board of community members), to more diffuse arrangements where a board of governors or a coalition of users is responsible for collective governance, but with effective (even if distant) constitutional governance actors. ${ }^{33}$ The rules configuration is diffuse when they are made, changed, monitored and enforced at more than one level rather than only one, and when there is space for contestation among actors across the three levels of governance. ${ }^{17}$

Consider a private-sector health facility that is operated without a governing board of community members in a setting where the government is distant or weak. ${ }^{1736}{ }^{37} \mathrm{In}$ such a private facility, there is essentially a collapse (or folding into one) of rules; a concentration of the power to make, change, monitor and enforce rules. The operational rules may reflect only whatever the owner decides the constitutional rules are, especially when it is an 'onsite' owner who is also the lead service provider. When off-site, the gap between constitutional rules (as interpreted by the owner) and operational rules may depend on the proximity of the owner. ${ }^{17}$ Or consider a health facility owned by a religious or ethnic organisation, with a governing board of community members who are also members of that same religious organisation or ethnicity, with constitutional rules made by the national leader of the religious organisation or ethnic group, supported by subnational deputies. Consider also that the health workers in that facility are also predominantly members of the religion or ethnicity. Here, although the three levels of government are present, the lack of diversity means that in effect, the power to make, change, monitor and enforce rules may remain concentrated. ${ }^{17}$

In such settings of concentrated power, it may be more or less easy for operational rules to align with local needs and realities, depending on socioeconomic and geographical factors. For example, our on-site owner of a private health facility may be governed only by the rules of the marketplace and may prioritise only the segment of the community that is able to afford high service charges. In contrast, our ethnic or religious service provider, governed by the predominant social values of one religion or ethnic group, may be deemed responsive to local needs, but only if the community that relies on the provider for health services is homogeneous ethnically or in following that religion. Notably, the presence of collective level actors (eg, on the demand side in the form of a governing board of community members or as professional, norm-setting association of health workers) is not enough to guarantee making, changing, monitoring and enforcing rules. Their management rights need to be well defined and protected. ${ }^{38} 39$ They need to have the capacity to make, change, monitor and enforce rules, and the geographical circumstances need to be sufficiently favourable. ${ }^{2340}$

\section{THINKING IN TWO TRIANGLES}

In my experience, there are three sets of potential advantages to using the 'triangle of rules' alongside the 'triangle of persons': (1) by focusing on information, it complements the 'triangle of persons' that focuses on accountability; (2) by focusing on structure, it complements the 'triangle of persons' that focuses on agency; and (3) by focusing on rules, it allows for the same person or groups of persons to take position at different nodes of the triangle, depending on the rules they influence and the rules that influence them.

\section{Information and accountability}

The 'triangle of rules' requires that analysts put information (and knowledge and feedback) on a similar pedestal as accountability. ${ }^{41}{ }^{42}$ Due to its origins, the 'triangle of persons' focuses on accountability. ${ }^{4}$ Rules generate and stem from accountability. But while information is necessary for accountability, it can also work simply by actors knowing the right thing to do and how. ${ }^{43}$ This is a fertile ground for comparative analyses: for example, what is the optimal strategy to improve governance-focus on information or accountability, or both? Is the answer different for various settings, functions or scales? What role can technology play in improving governance, given its potential to alter the epistemic properties of rule configurations? For example, technology can change the meaning of proximity if it makes monitoring and enforcement of rules at a distance less costly, ${ }^{16} 363741$ which may also lead to less flexibility and freedom to determine rules-in-use locally.

The 'triangle of rules' also has the potential to expose the analyst to their own limited knowledge, compel (through systems thinking) the analyst to assume the standpoint of many "others ${ }^{44}$ and thus enable a richer appreciation of the complex and adaptive nature of health systems. The positionality (pose) of the analyst matters. ${ }^{45}$ For example, how well can analysts see the 


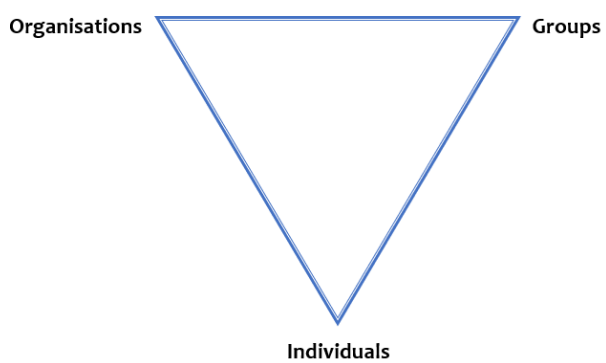

Triangle of Persons

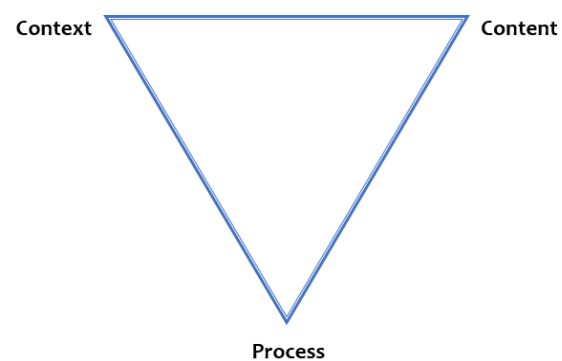

Policy Analysis Triangle

Figure 5 The policy analysis triangle(s) showing the multitude of factors (context, content and process) affecting policy and the relations among these factors, and 'persons' interacting as individuals, or as part of groups, and organisations to influence the policy context, content and process.

granularity of rules at a distance? ${ }^{1}{ }^{47}$ Using the 'triangle of rules' can remind the analyst of the limits to their sight when trying to see at a distance or with limited information on the granular details of context.

\section{Structure and agency}

The 'triangle of persons' focuses on what persons do, that is, agency, whereas the 'triangle of rules' focuses on the institutional structures that constrain and enable such agency. In the eternal debate on the relative importance of structure vs agency, ${ }^{48}$ an analyst may assume that their potential to change peoples' choices is greater than their potential to change the rules that constrain or enable those choices. However, trying to change people without changing rules (eg, by appealing to 'the better angels of their nature') may have less potential to be effective (especially when acting at a distance) than trying to change structures. Global health typically involves acting 'at a distance', ${ }^{50}$ often with less than optimal local knowledge or agency or stake (ie, 'skin in the game'). Perhaps, what an analyst can best offer at a distance are design features, based on bottom-up synthesis, and abstraction of learning and insight from comparative analyses across settings. ${ }^{475152}$

This tension often goes unacknowledged: What can a distant (or foreign) analyst really say about governance? What are the limits? The triangle of rules sheds light on potential strategies to alter structure-for example, on how to decentralise governance in a way that facilitates community engagement in governance. ${ }^{43} 53$ But the closer governing the entities are to the ground, the more prone to, say, nepotism, and the lower the ability of central governing entities to impose beneficial equalising measures top down. ${ }^{43}$ The 'triangle of rules' may inform comparative analyses to identify 'optimal' points for decentralised governance while minimising negative consequences-a design feature (ie, structure) that may be understood in the abstract and influenced at a distance. $^{52}$

\section{Rules and persons}

Thinking in two triangles also requires analysts to shift back and forth between persons and rules. In doing so, rules allow persons to be moved, between nodes, depending on the rules they influence, the rules that influence them-the governance issue under consideration. ${ }^{18}$ The same person may function as a service provider or user (operational), a community leader (collective) and a legislator (constitutional). Likewise, the same governing entity may also function at different levels depending on size and distance: the council of chiefs in a town of 2000 people may function at the collective level of governance. If the town grows to a population of 200000 people, the council of chiefs may then function at the constitutional level of governance. And while two towns may have similar governing entities by name (eg, each with its own council of chiefs), the different sizes of each town may mean that each council makes different kinds of rules. ${ }^{17}$ In a large town where the council is distant from the operational level, it may function at the constitutional level, with smaller self-organising community entities emerging to take on collective governance.

In addition, analysis can be conducted at varying scales, for example, from the governance of a district health system to a national health system, even the dynamics of global health governance, for example, due to the COVID-19 pandemic, personal protective equipment is now governed by global markets (operational level), but also at the collective level (eg, groups of countries coming together, or not, to govern the market to promote collective good) and the constitutional level (potentially through the WHO or using the 'constitutional' rules contained in the International Health Regulations). ${ }^{54}$

\section{CONCLUSION}

What is said of models is true of frameworks; all frameworks are partial, but some are useful. Together with the 'triangle of rules', the health system governance 'triangle of persons' is more useful. The need for such a second triangle is not peculiar, as in the case of Malan's two triangles used in psychoanalytic psychotherapy. However, there is yet another, although less apparent, instance of a two-triangle framework. One cannot, must not, write about triangles in health systems or global health without paying much-deserved homage to the most widely used 
of them all-Walt and Gilson's policy analysis triangle, ${ }^{55}$ which, indeed, also demonstrates the limits of a single triangle. In addition to the three nodes of the policy analysis triangle-context, content and process-Walt and Gilson included actors (ie, 'persons') in their various roles as individuals, groups and organisations. ${ }^{56}$ It could easily have been a 'triangle of persons', thus, making two triangles (figure 5).

One triangle is not enough. The 'triangle of rules' highlights often ignored features of health systems that are worth keeping in mind in efforts to understand and improve their governance, features that can easily be missing if or when the 'triangle of persons' is used alone. In making the case for this complementary 'triangle of rules', I have pointed at potential middle-range theories, transferable insights and lines of inquiry, which may animate comparative analyses of health system governance and also inform efforts to strengthen it. ${ }^{57-59}$ What I have tried to do in this editorial essay, as Ronald Coase once said, "has been to urge the inclusion in our analysis, of features of the (health) system so obvious that... they have tended to be overlooked'. ${ }^{60}$ The language of rules (or institutions) and their configurations (or arrangements), the middle-range theories they suggest, and the analytical stance they require, may yet improve our analysis of health system governance.

Twitter Seye Abimbola @seyeabimbola

Acknowledgements The author thanks Aliki Christou (University of Sydney), Dorothy Drabarek (University of Sydney), Veena Sriram (University of Chicago) and Kenneth Yakubu (The George Institute, Sydney) for their insightful comments on earlier drafts of this editorial.

Funding The author is currently supported by the National Health and Medical Research Council (NHMRC) of Australia through an Overseas Early Career Fellowship (APP1139631).

Competing interests The author is the Editor in Chief of BMJ Global Health Patient consent for publication Not required.

Provenance and peer review Not commissioned; internally peer reviewed.

Data availability statement There are no data in this work.

Open access This is an open access article distributed in accordance with the Creative Commons Attribution Non Commercial (CC BY-NC 4.0) license, which permits others to distribute, remix, adapt, build upon this work non-commercially, and license their derivative works on different terms, provided the original work is properly cited, appropriate credit is given, any changes made indicated, and the use is non-commercial. See: http://creativecommons.org/licenses/by-nc/4.0/.

ORCID iD

Seye Abimbola http://orcid.org/0000-0003-1294-3850

\section{REFERENCES}

1 Poteete AR, Janssen MA, Ostrom E. Working Together: Collective Action, the Commons, and Multiple Methods in Practice. Princeton, NJ: Princeton University Press, 2010.

2 Abimbola S, Negin J, Martiniuk AL, et al. Institutional analysis of health system governance. Health Policy Plan 2017;32:1337-44.

3 Bigdeli M, Rouffy B, Lane BD, et al. Health systems governance: the missing links. BMJ Glob Health 2020;5:e002533.

4 The World Bank. World Development Report 2004: Making Services Work for Poor People. Washington, DC, 2004. http:// documents.worldbank.org/curated/en/527371468166770790/WorldDevelopment-Report-2004-Making-services-work-for-poor-peopleOverview
5 Brinkerhoff DW, Bossert TJ. Health governance: principal-agent linkages and health system strengthening. Health Policy Plan 2014;29:685-93.

6 Pyone $\mathrm{T}$, Smith $\mathrm{H}$, van den Broek N. Frameworks to assess health systems governance: a systematic review. Health Policy Plan 2017;32:710-22.

7 Cleary SM, Molyneux S, Gilson L. Resources, attitudes and culture: an understanding of the factors that influence the functioning of accountability mechanisms in primary health care settings. BMC Health Serv Res 2013;13:320.

8 Meessen B. Health system governance: welcoming the reboot. BMJ Glob Health 2020;5:e002404.

9 Malan DH. Individual Psychotherapy and the Science of Psychodynamics. Butterworth-Heinemann: Oxford, 1979.

10 Osimo F, Stein MJ. Theory and Practice of Experiential Dynamic Psychotherapy. London: Routledge, 2012.

11 Lilliengren $\mathrm{P}$, Johansson R, Lindqvist $\mathrm{K}$, et al. Efficacy of experiential dynamic therapy for psychiatric conditions: a meta-analysis of randomized controlled trials. Psychotherapy 2016;53:90-104.

12 Johansson R, Björklund M, Hornborg C, et al. Affect-focused psychodynamic psychotherapy for depression and anxiety through the Internet: a randomized controlled trial. PeerJ 2013;1:e102.

13 Ostrom E, Gardner R, Rules WJ. Games, and Common-Pool Resources. Ann Arbor, MI: University of Michigan Press, 1994.

14 McGinnis MD. An introduction to IAD and the language of the Ostrom workshop: a simple guide to a complex framework. Policy Stud J 2011;39:169-83.

15 Kiser LL, Ostrom E. The Three Worlds of Action: A Metatheoretical Synthesis of Institutional Approaches. In: Ostrom E, ed. Strategies of Political Inquiry. Beverly Hills :CA: Sage, 1982: 179-222.

16 Polski MM, Ostrom E, Cole DH, et al. An Institutional Framework for Policy Analysis and Design. In: Elinor Ostrom and the Bloomington school of political economy, volume 3, a framework for policy analysis. London: Lexington Books, 2017: 13-48.

17 Bushouse BK. Governance structures: using IAD to understand variation in service delivery for Club goods with information asymmetry. Policy Stud J 2011;39:105-19.

18 Abimbola S, Negin J, Jan S, et al. Towards people-centred health systems: a multi-level framework for analysing primary health care governance in low- and middle-income countries. Health Policy Plan 2014;29:ii29-39.

19 Abimbola S, Ukwaja KN, Onyedum CC, et al. Transaction costs of access to health care: implications of the care-seeking pathways of tuberculosis patients for health system governance in Nigeria. Glob Public Health 2015;10:1060-77.

20 Abimbola S, Ogunsina K, Charles-Okoli AN, et al. Information, regulation and coordination: realist analysis of the efforts of community health committees to limit informal health care providers in Nigeria. Health Econ Rev 2016;6:51.

21 Godlonton S, Okeke EN. Does a ban on informal health providers save lives? Evidence from Malawi. J Dev Econ 2016;118:112-32.

22 Reid A. Birth attendants and midwifery practice in early twentiethcentury Derbyshire. Social History of Medicine 2012;25:380-99.

23 Abimbola S. Beyond positive a priori bias: reframing community engagement in LMICs. Health Promot Int 2020;35:598-609.

24 Dixit A. Governance institutions and economic activity. Am Econ Rev 2009;99:5-24.

25 Abimbola S, Molemodile SK, Okonkwo OA, et al. 'The government cannot do it all alone': realist analysis of the minutes of community health committee meetings in Nigeria. Health Policy Plan 2016;31:332-45.

26 Onwujekwe O, Agwu P, Orjiakor C, et al. Corruption in Anglophone West Africa health systems: a systematic review of its different variants and the factors that sustain them. Health Policy Plan 2019;34:529-43.

27 Onwujekwe O, Orjiakor CT, Hutchinson E, et al. Where do we start? Building consensus on drivers of health sector corruption in Nigeria and ways to address it. Int J Heal Policy Manag 2020;9:286-96.

28 Abimbola S, Olanipekun T, Schaaf M, et al. Where there is no policy: governing the Posting and transfer of primary health care workers in Nigeria. Int J Health Plann Manage 2017;32:492-508.

29 Abimbola S, Olanipekun T, Igbokwe U, et al. How decentralisation influences the retention of primary health care workers in rural Nigeria. Glob Health Action 2015;8:26616.

30 Boettke PJ. F. A.Hayek: Economics, Political Economy and Social Philosophy. London: Palgrave Macmillan, 2018.

31 Lewis PA. Epistemic Institutionalism: rules and order, complexity, and Liberalism. Cosm + Taxis Stud Emergent Order Organ 2020;7:50-60. 
32 Barasa EW, Manyara AM, Molyneux S, et al. Recentralization within decentralization: county hospital autonomy under devolution in Kenya. PLoS One 2017;12:e0182440.

33 Munthopa LA, TB MH, Cythia BR. Emerging structural models for governance of public hospitals. Int J Heal Gov 2019;24:98-116.

34 Mabuchi S, Sesan T, Bennett SC. Pathways to high and low performance: factors differentiating primary care facilities under performance-based financing in Nigeria. Health Policy Plan 2018;33:41-58.

35 Loevinsohn BP, Conlon MK, Zeng W, et al. Impact Evaluation of Nigeria State Health Investment Project [Internet. Washington, DC, 2019. http://documents.worldbank.org/curated/en/ 589301552969360031/Impact-Evaluation-of-Nigeria-State-HealthInvestment-Project

36 Bloom $\mathrm{G}$, Wilkinson A, Standing $\mathrm{H}$, et al. Engaging with health markets in low and middle-income countries. IDS Working Papers 2014;2014:1-28.

37 Champion C, Bloom G, Peters DH. Evidence of the effects of market-based innovations and international initiatives to improve the performance of private providers. In: Bloom G, Kanjilal B, Lucas H, et al, eds. Transforming health markets in Asia and Africa improving quality and access for the poor. London: Routledge, 2012: 130-42.

38 Lodenstein E, Dieleman M, Gerretsen B, et al. Health provider responsiveness to social accountability initiatives in low- and middle-income countries: a realist review. Health Policy Plan 2017;32:125-40.

39 George A, Scott K, Garimella S, et al. Anchoring contextual analysis in health policy and systems research: a narrative review of contextual factors influencing health committees in low and middle income countries. Soc Sci Med 2015;133:159-67.

40 Falisse J-B, Meessen B, Ndayishimiye J, et al. Community participation and voice mechanisms under performance-based financing schemes in Burundi. Trop Med Int Heal 2012;17:674-82.

41 Ostrom E, Gibson C, Shivakumar S, et al. The Institutional Analysis and Development Framework. In: Cole DH, McGinnis MD, eds. Elinor Ostrom and the Bloomington School of Political Economy, volume 3, A Framework for Policy Analysis. London: Lexington Books, 2017: 49-86.

42 Pennington M. Elinor Ostrom and the robust political economy of common-pool resources. Journal of Institutional Economics 2013;9:449-68.

43 Abimbola S, Baatiema L, Bigdeli M. The impacts of decentralization on health system equity, efficiency and resilience: a realist synthesis of the evidence. Health Policy Plan 2019;34:605-17.

44 Arendt $\mathrm{H}$. Truth and Politics. In: Arendt H, ed. Between Past and Future: Eight Exercises in Political Thought. London: Penguin Books, 1968: 227-64.
45 Abimbola S. The foreign gaze: authorship in academic global health. BMJ Glob Health 2019;4:e002068.

46 Gilmore B. Realist evaluations in low- and middle-income countries: reflections and recommendations from the experiences of a foreign researcher. BMJ Glob Health 2019;4:e001638.

47 Stiglitz J. Scan Globally, Reinvent Locally: Knowledge Infrastructure and the Localisation of Knowledge. In: Stone D, ed. Banking on Knowledge. London: Routledge, 2001: 25-44.

48 Harris P, Baum F, Friel S, et al. A glossary of theories for understanding power and policy for health equity. J Epidemiol Community Health 2020;74:jech-2019-213692-552.

49 Porter S. The uncritical realism of realist evaluation. Evaluation 2015;21:65-82.

50 Abimbola S. On the meaning of global health and the role of global health journals. Int Health 2018;10:63-5.

51 Taleb NN. Skin in the Game: Hidden Asymmetries in Daily Life. New York, NY: Random House, 2017

52 Ostrom E. Understanding Institutional Diversity. Princeton, NJ: Princeton University Press, 2005.

53 Topp SM, Abimbola S, Joshi R, et al. How to assess and prepare health systems in low- and middle-income countries for integration of services-a systematic review. Health Policy Plan 2018;33:298-312.

54 Ferhani A, Rushton S. The International Health Regulations, COVID-19, and bordering practices: who gets in, what gets out, and who gets rescued? Contemp Secur Policy 2020;41:458-77.

55 Walt G, Gilson L. Reforming the health sector in developing countries: the central role of policy analysis. Health Policy Plan 1994;9:353-70.

56 Buse K, Dickinson C, Gilson L, et al. How can the analysis of power and process in policy-making improve health outcomes? Moving the agenda forward. Briefing Paper 25. London2007. https://www.odi. org/sites/odi.org.uk/files/odi-assets/publications-opinion-files/478. pdf

57 Ridde V. Need for more and better implementation science in global health. BMJ Glob Health 2016;1:e000115.

58 Van Belle S, van de Pas R, Marchal B. Towards an agenda for implementation science in global health: there is nothing more practical than good (social science) theories. BMJ Glob Health 2017;2:e000181.

59 Ridde V, Pérez D, Robert E. Using implementation science theories and frameworks in global health. BMJ Glob Health 2020;5:e002269.

60 Coase $\mathrm{RH}$. The Institutional Structure of Production. In: Coase RH, ed. Essays on Economics and Economists. Chicago: The University of Chicago Press, 1994: 3-14. 